\title{
Contraception and pregnancy in microbicide trials
}

\author{
Sengeziwe Sibeko, MB ChB, FCOG, MS, Research Gynaecologist ${ }^{\mathrm{a}, *}$, \\ Gabriel M. Cohen, BA, Fogarty International Clinical Research Scholar ${ }^{\mathrm{a}, \mathrm{b}}$, \\ Jagidesa Moodley, MB ChB, FRCOG, MD, Emeritus Professor ${ }^{c}$ \\ ${ }^{a}$ Centre for the AIDS Programme of Research in South Africa (CAPRISA), 2nd Floor Doris Duke Medical Research Institute, \\ Nelson R Mandela School of Medicine, University of KwaZulu-Natal, Private Bag X7, Congella, 4013, Durban, South Africa \\ ${ }^{\mathrm{b}}$ New York University School of Medicine, New York, NY 10016, United States \\ ${ }^{\mathrm{c}}$ Women's Health and HIV Research Group, Department of Obstetrics and Gynaecology, University of KwaZulu-Natal, \\ Congella, South Africa
}

\section{Keywords:}

HIV

microbicides

pregnancy

contraception

\begin{abstract}
The distinctive feature of the human immunodeficiency virus (HIV) epidemic in Sub-Saharan Africa is the burden on women, in particular young women of reproductive age. Consequently, most late-phase effectiveness microbicide clinical trials are conducted in sub-Saharan Africa where fertility rates are high. Because latephase clinical trials are conducted over prolonged periods of time, women participating in these trials may fall pregnant during the trial. Their unborn babies may be exposed to a drug whose teratogenic potential is unknown if the investigational drug is not withdrawn. High pregnancy rates in such trials may compromise statistical integrity, as women will be withdrawn from the study drug for the duration of the pregnancy. It is therefore imperative for microbicide trials to implement effective contraceptive and pregnancy management programmes that maintain low pregnancy rates and the safety of unborn babies while not compromising the conduct and statistical integrity of the trial.
\end{abstract}

(c) 2012 Elsevier Ltd. All rights reserved.

\section{Introduction}

A distinctive feature of the human immunodeficiency virus (HIV) epidemic in the 21st century is its increasing burden in women, particularly young women. Women now account for about one-half of all people living with HIV, and for more than $60 \%$ of new infections in Africa, where heterosexual

\footnotetext{
* Corresponding author. Tel: +44 (0) 1865 222419; Fax: +44 (0) 1865222502.

E-mail address: sengeziwe.sibeko@ndm.ox.ac.uk (S. Sibeko).
} 
transmission is the primary driver of the epidemic. ${ }^{1}$ Africa is the only region where this occurs, with young women in the reproductive age group bearing the brunt of the epidemic. This is also the region where fertility rates are high as a result of cultural norms and expectations, and where socio-cultural gender dynamics prevail in sexual relationships. This affects a woman's ability to make independent decisions about her sexual and reproductive health, often negatively.

Barrier contraceptive methods are an effective HIV and pregnancy prevention strategy; however, many women in Africa are unable to negotiate successfully their use with male partners, often for socio-cultural reasons. Therefore, a method that women can initiate or control is urgently required. As a result of the shortfall of barrier contraceptive methods to protect women against HIV acquisition, a topical virucide that could block HIV transmission by the vaginal route was suggested as an alternative strategy in $1990 .^{2}$ Since then, three generations of various intravaginally administered microbicides, with varying mechanisms of actions, have been tested. To date, one antiretroviral-based and 12 non-antiretroviral-based microbicide effectiveness trials among women have taken place to assess their effect on the prevention of HIV infection, with varying success rates ${ }^{3}$ (Table 1 ). The $14^{\text {th }}$ trial implemented in 2009 is currently ongoing, and its results are anticipated early in 2013. ${ }^{4}$ The most recent to be implemented is the South African study, FACTS 001, with an anticipated completion date in $2013 .^{5}$

One of the greatest challenges in conducting these trials has been the associated high pregnancy rates. ${ }^{6-8}$ In clinical trials of experimental drugs where teratogenic effects on the fetus are not fully understood, participants who become pregnant during the trial may be taken off the product for safety reasons. Microbicides are relatively new developmental drugs whose pharmacokinetics and pharmacodynamics are not completely understood. They act locally, however, and their systemic absorption is either minimal and transient or unlikely, and trans-placental fetal exposure via systemic circulation is therefore likely to be insignificant. Taking pregnant women off the study drug may be a prudent cautionary option, as no specific guidelines are available for their inclusion in late-phase clinical trials. In microbicide trials, high pregnancy rates with discontinued product use have implications for the design, conduct and generalisability of the results, including the loss of power and effect size of the study outcome in an intention-to-treat analysis. ${ }^{7}$

To address the challenges of high pregnancy rates and potential adverse pregnancy-related outcomes, various trials have implemented different strategies with varying levels of success. Although some trials reported pregnancy rates as high as 64 per 100 person years with time off product loss as high as 151 per 100 person years, ${ }^{9}$ recently completed trials have achieved pregnancy rates as low as four per 100 person years with negligible time off product lost. ${ }^{10}$ In this publication, strategies used by previously completed trials to enhance contraceptive use and reduce pregnancy rates while maintaining the safety of the fetus are reviewed. The successes and failures based on the respective strategies as measured by contraceptive uptake and pregnancy rates are compared. On the basis of these outcomes, strategies that may be selected for future use in these trials are recommended, and gaps in current knowledge are identified.

\section{Contraceptive use management}

\section{Need for a contraceptive programme}

Of the estimated 208 million pregnancies that occurred in 2008, about 86 million were unintended, of which 33 million resulted in unplanned births, 41 million in abortions, and the remaining 11 million in spontaneous miscarriages. ${ }^{11}$ Although some unintended pregnancies occur in women on a contraceptive method as a result of method failure with either typical or perfect use, others occur in women who are not on a contraceptive method at all. Outside of research, almost one-half of unintended pregnancies occur in women not on any contraceptive method. The Guttmatcher researchers reported that, in 2001, almost one-half of the 6.4 million pregnancies in the USA were unintended and, in $52 \%$ of these, no contraceptive method was used during the month of conception. ${ }^{12}$ It is essential, therefore, to prevent or reduce unintended pregnancies and minimise the sequalae on the efficiency of trial conduct and statistical integrity. An intensive contraceptive programme has to be implemented in any microbicide trial. 
Table 1

Microbicide trials to date.

\begin{tabular}{|c|c|c|c|c|c|c|c|c|}
\hline Microbicide trial & Study product & $\begin{array}{l}\text { Study } \\
\text { Phase }\end{array}$ & $\begin{array}{l}\text { Number } \\
\text { enrolled }(\mathrm{N})\end{array}$ & $\begin{array}{l}\text { Number } \\
\text { included } \\
\text { in analysis }(\mathrm{N})\end{array}$ & Age (years) & $\begin{array}{l}\text { Study } \\
\text { population }\end{array}$ & $\begin{array}{l}\text { Study } \\
\text { duration }\end{array}$ & $\begin{array}{l}\text { Study } \\
\text { sites }\end{array}$ \\
\hline \multicolumn{9}{|l|}{ Surfactants } \\
\hline Kenya N-9 Sponge Trial ${ }^{13}$ & N-9 & III & 138 & $116^{\mathrm{a}}$ & - & Female sex worker & $1987-1990$ & Kenya \\
\hline FHI N-9 Film Trial ${ }^{14}$ & N-9 & III & 1292 & $1170^{\mathrm{a}}$ & $18-45$ & Female sex worker & 1994- 1996 & Cameroon \\
\hline Low-dose N-9 gel Trial ${ }^{15}$ & N-9 & III & 278 & $262^{\mathrm{a}}$ & $18-48$ & Female sex worker & $1996-1998$ & Kenya \\
\hline UNAIDS COL-1492 Trial $^{16}$ & $\mathrm{~N}-9$ & II/III & 892 & $765^{\mathrm{a}}$ & over $18^{\mathrm{b}}$ & Female sex worker & $1996-2000$ & $\begin{array}{l}\text { Benin, Côte d'Ivoire, } \\
\text { South Africa, Thailand }\end{array}$ \\
\hline FHI Savvy Trial/Ghana ${ }^{9}$ & C31G & III & 2142 & $2038^{\mathrm{a}}$ & $18-35$ & Sexually active & 2004-2005 & Ghana \\
\hline FHI Savvy Trial/Nigeria ${ }^{20}$ & C31G & III & 2153 & $2082^{\mathrm{a}}$ & $18-35$ & Sexually active & 2004-2006 & Nigeria \\
\hline \multicolumn{9}{|l|}{ Buffers and blockers } \\
\hline $\begin{array}{l}\text { CONRAD Cellulose Sulfate } \\
\text { Trial }^{c, 17}\end{array}$ & Cellulose sulfate & III & 1147 & $1122^{\mathrm{a}}$ & over 18 & Sexually active & 2005-2007 & $\begin{array}{l}\text { Benin, India, South } \\
\text { Africa, Uganda }\end{array}$ \\
\hline FHI CS Trial ${ }^{18}$ & Cellulose sulfate & III & 1644 & $1506^{\mathrm{a}}$ & $18-35$ & Sexually active & 2004-2007 & Nigeria \\
\hline $\begin{array}{l}\text { Population Council } \\
\text { Carraguard Trial }^{25}\end{array}$ & Carraguard $^{\circledR}$ & III & 6202 & $6005^{\mathrm{d}}$ & over 16 & Sexually active & 2004-2007 & South Africa \\
\hline $\begin{array}{l}\text { MDP } 301 \text { (0.5\% \& 2\% PRO } \\
2000)^{26}\end{array}$ & PRO $2000^{\circledR}$ & III & 9385 & $8859^{a}$ & over $18^{e}$ & Sexually active & $2005-2008$ & $\begin{array}{l}\text { South Africa, Tanzania, } \\
\text { Uganda and Zambia }\end{array}$ \\
\hline $\begin{array}{l}\text { HPTN } 0350.5 \% \text { PRO } 2000 \\
\text { and Buffergel }{ }^{\circledR} \text { Trial }^{24}\end{array}$ & $\begin{array}{l}\text { PRO } 2000^{\circledR} \text { and } \\
\text { Buffergel }^{\circledR}\end{array}$ & $\mathrm{II} / \mathrm{IIb}$ & 3087 & $3050^{\mathrm{a}}$ & over 18 & Sexually active & 2005-2009 & $\begin{array}{l}\text { Malawi, South Africa, } \\
\text { Zambia, Zimbabwe, } \\
\text { USA }\end{array}$ \\
\hline \multicolumn{9}{|l|}{ Antiretroviral drugs } \\
\hline $\begin{array}{l}\text { CAPRISA 004 Tenofovir } \\
\text { gel Trial }^{10,22}\end{array}$ & Tenofovir & $\mathrm{II} / \mathrm{IIb}$ & 1085 & $889^{\mathrm{f}}$ & $18-40$ & Sexually active & $2007-2010$ & South Africa \\
\hline MTN 003 VOICE Trial ${ }^{4}$ & Tenofovir & IIb & Ongoing & Ongoing & $18-45$ & Sexually active & 2009- Present & $\begin{array}{l}\text { South Africa, Uganda, } \\
\text { Zimbabwe }\end{array}$ \\
\hline FACTS 001 Trial $^{5}$ & Tenofovir & III & Ongoing & Ongoing & $18-30$ & Sexually active & 2011-Present & South Africa \\
\hline
\end{tabular}

CAPRISA, Centre for the AIDS Programme of Research in South Africa; CONRAD, Contraceptive Research and Development; FACTS, Follow-on African Consortium for Tenofovir Studies; FHI Family Health International; HPTN, HIV Prevention Trials Network; N-9, Nonoxynol-9; MDP, Microbicide Development Programme; MTN, Microbicide Trials Network; VOICE, Vaginal and Oral Interventions to Control the Epidemic.

Dash: Data not available.

a Sample size based on a subset of the intent-to-treat population for whom at least one post-enrollment HIV evaluation is available.

b In South Africa the age was 16 years or older.

${ }^{c}$ Data from the two sites in India (Chennai, Bangalore) were not included in this analysis because only two pregnancies were observed in those sites and because of the high prevalence of surgical sterilisation. See Halpern et al (2011). ${ }^{31}$

d Individuals were excluded from the analysis if they did not have at least one post-enrolment HIV evaluation, if they had window period seroconversion, or if they only returned unused applicators.

e In Tanzania and Uganda, the age was 16 years or older.

${ }^{\mathrm{f}}$ Individuals were excluded from the analysis if they they did not have at least one post-enrolment HIV evaluation, were co-enrolled in another microbicide trial, were in a microbicide trial less than 12 months ago, or had window period seroconversion. 
Besides the mismatch in pregnancy intentions and contraceptive use behaviour, women may not be on a contraceptive method for other reasons, including poor access and availability owing to high cost and unavailable or limited family planning services. It is important that microbicide trials endorse strategies that make contraceptives widely accessible and available, but also accentuate contraceptive uptake and use. Researchers conducting microbicide trials should promote the use of highly effective and reliable contraceptives throughout the study period in order to keep rates of unplanned and unwanted pregnancies to a minimum. Strategies from screening and enrolment through to follow up and exit visits have been used by various microbicide studies with varying degrees of success (Table 2).

\section{Eligibility criteria}

Early trials implemented before 2007 studying the first two generations of non anti-retroviralbased microbicides (i.e. the surfactants and polymers), did not specify contraceptive use as an eligibility criterion for trial participation (Table 2). Perhaps that was understandable given that some of the earlier microbicide agents such, as nonoxynol $9,{ }^{13-16}$ a spermicide, and cellulose sulphate, ${ }^{17,18}$ an entry inhibitor, also possessed a primary underlying contraceptive effect. ${ }^{12}$ Pregnancy rates were not high in the nonoxynol 9 trials, and were found to be comparable to those of cellulose sulphate (CS) as established in a (CS) non-comparative trial. ${ }^{19}$ In addition, this was in the early days of microbicide trials before the scale of the effect of high pregnancy rates could be appreciated. A first meeting of experts to discuss pregnancy-related challenges in microbicide trials was convened in 2005. This was a culmination of lessons learned from ongoing trials in the field, with pregnancy rates as high as 64 and 37 per 100 person years overall in the Savvy/Ghana and Savvy/Nigeria trials, respectively ${ }^{9,20}$ and 76 per 100 person years in one of the Ghana sites. ${ }^{8}$ In the meeting, a recommendation to specify contraceptive-related eligibility criteria among others was made. ${ }^{6}$ Subsequent discussions by experts in the field occurred at the 2006 microbicide conference in Cape Town, ${ }^{8}$ and again at the pregnancy and contraception in microbicide clinical development meeting in 2009. ${ }^{21}$

Microbicide trials implemented after this era, such as CAPRISA 004 implemented in $2007,{ }^{10}$ MTN 003 implemented in 2009, ${ }^{4}$ and FACTS 001 implemented in 2011, ${ }^{5}$ specified contraceptive-related eligibility criteria, including enrolment of women on a pre-specified eligible type of contraceptive method. To date, CAPRISA $004^{10}$ is the only published study that included contraceptive use as an eligibility criteria and enrolled women with documented evidence of contraceptive use (Table 2). These women were counselled. If they voluntarily opted for contraceptive use at screening, they were commenced on a contraceptive method. Consequently, it is the only study with $100 \%$ contraceptive uptake at baseline. $^{22}$

Recent studies on microbicides have used various specifications to define an eligible method of contraception, ranging from reliable to effective to non-barrier methods. The definition of an "effective" method was based on the conventional typical use rates characterised by a pregnancy risk of 3\% or less in the first year of use. ${ }^{23}$ Additionally, in the context of these trials, other attributes to consider would be a method that is less user dependant, less likely to be used inconsistently, and with less provider training requirements. ${ }^{6}$ The CAPRISA $004^{10}$ trial had inclusion criteria for non-barrier methods of contraception. This strategy was based on the high probability of inconsistent use of barrier methods which could result in higher pregnancy rates. Barrier methods, however, were promoted and supplied widely, but were promoted as part of risk-reduction counselling to reduce the acquisition and transmission of sexually transmitted infections, HIV and other reproductive infections. This strategy was included in the comprehensive contraceptive curriculum used and implemented by the CAPRISA 004 trial, ${ }^{10}$ which achieved around $80 \%$ uptake of long-acting injectable contraceptive methods during the trial. ${ }^{22}$

Some concerns have been raised with pre-specifying contraceptive eligibility criteria. One concern is that it may compromise enrolment targets. This was not evident in CAPRISA 004, ${ }^{10}$ however. Of the total number of 2160 women screened, only 26 out of 1075 women did not fulfil the criteria of trial entry of not being on an eligible contraceptive method. ${ }^{22}$ Another ethical concern with pre-specifying contraceptive-related eligibility criteria is that it might be misinterpreted as 
Table 2

Contraception management in microbicide trials to date.

\begin{tabular}{|c|c|c|c|c|c|c|c|c|c|c|c|c|c|c|}
\hline \multirow[t]{2}{*}{ Microbicide trial } & \multicolumn{2}{|l|}{ Screening } & \multicolumn{6}{|l|}{ Enrolment } & \multicolumn{2}{|l|}{ Follow up } & \multicolumn{3}{|l|}{ Provision } & \multirow{2}{*}{$\begin{array}{l}\text { Exit } \\
\text { Not using } \\
\text { contraception } \\
(\%)\end{array}$} \\
\hline & $\begin{array}{l}\text { Contraception } \\
\text { Use }\end{array}$ & $\begin{array}{l}\text { Eligible } \\
\text { method } \\
\text { prespecified }\end{array}$ & $\begin{array}{l}\text { Not using } \\
\text { contraception } \\
\text { (\%) }\end{array}$ & $\begin{array}{l}\text { Oral } \\
\text { contraceptive } \\
\text { pills (\%) }\end{array}$ & & $\begin{array}{l}\text { Injectables } \\
(\%)\end{array}$ & $\begin{array}{l}\text { Condom/ } \\
\text { barrier (\%) }\end{array}$ & Other (\%) & $\begin{array}{l}\text { Frequency } \\
\text { of visits }\end{array}$ & $\begin{array}{l}\text { Assessment } \\
\text { of method } \\
\text { frequency }\end{array}$ & $\begin{array}{l}\text { On-site } \\
\text { provision }\end{array}$ & Free & $\begin{array}{l}\text { Methods } \\
\text { other than } \\
\text { condoms }\end{array}$ & \\
\hline \multicolumn{15}{|l|}{ Surfactants } \\
\hline Kenya N-9 Sponge Trial ${ }^{13}$ & No & No & - & 25 & & - & - & - & Monthly & Exit & No & - & - & - \\
\hline FHI N-9 Film Trial ${ }^{14}$ & No & No & $87^{\mathrm{a}}$ & - & $5^{\mathrm{a}, \mathrm{b}}$ & - & - & $8^{\mathrm{a}}$ & Monthly & - & No & - & - & - \\
\hline Low-dose N-9 gel Trial ${ }^{15}$ & No & No & 49 & 14 & & 15 & 11 & 7 & Monthly & - & No & - & - & - \\
\hline UNAIDS COL-1492 Trial ${ }^{16}$ & No & No & - & - & & - & - & - & Monthly & - & No & - & - & - \\
\hline FHI Savvy Trial/Ghana & No & No & $39^{\mathrm{a}}$ & $12^{\mathrm{a}}$ & & $2^{\mathrm{a}}$ & $47^{\mathrm{a}}$ & $0.6^{\mathrm{a}}$ & Monthly & - & No & - & $\begin{array}{l}\text { Family planning } \\
\text { counselling }\end{array}$ & - \\
\hline FHI Savvy Trial/Nigeria ${ }^{20, d}$ & No & No & $8^{\mathrm{a}}$ & $15^{\mathrm{a}}$ & & $1^{\mathrm{a}}$ & $75^{\mathrm{a}}$ & $1^{\mathrm{a}}$ & Monthly & - & No & - & $\begin{array}{l}\text { Family planning } \\
\text { counselling }^{\mathrm{c}}\end{array}$ & - \\
\hline \multicolumn{15}{|l|}{ Buffers and blockers } \\
\hline $\begin{array}{l}\text { CONRAD Cellulose Sulfate } \\
\text { Trial }{ }^{17, d}\end{array}$ & No & No & $13^{\mathrm{a}}$ & $8^{\mathrm{a}}$ & & $24^{\mathrm{a}}$ & $47^{\mathrm{a}}$ & $9^{\mathrm{a}}$ & Monthly & - & Yes $^{e}$ & Yes & OCPs, Injectables & - \\
\hline FHI CS Trial ${ }^{18, d}$ & No & No & $27^{\mathrm{a}}$ & $16^{\mathrm{a}}$ & & $1^{\mathrm{a}}$ & $55^{\mathrm{a}}$ & $0.3^{\mathrm{a}}$ & Monthly & - & No & - & $\begin{array}{l}\text { Family planning } \\
\text { counselling }^{\mathrm{c}}\end{array}$ & - \\
\hline $\begin{array}{l}\text { Population Council Carraguard } \\
\text { Trial }^{25, f}\end{array}$ & No & No & 23 & 8 & & 42 & 18 & 14 & Quarterly & Quarterly & Yes $^{e}$ & Yes & OCPs, injectables & 20 \\
\hline $\begin{array}{l}\text { MDP } 301(0.5 \% \text { and } 2 \% \text { PRO } \\
2000 \circledast)^{26}\end{array}$ & No & No & - & - & $56^{g}$ & - & - & - & Monthly & - & Yes & Yes & OCPs, injectables, IUD ${ }^{\mathrm{h}}$ & - \\
\hline 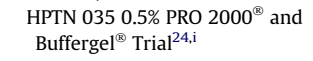 & No & No & - & 20 & & 48 & - & - & Monthly & Quarterly & Yes $^{e}$ & Yes & OCPs, injectables & - \\
\hline \multicolumn{15}{|l|}{ Antiretroviral drugs } \\
\hline $\begin{array}{l}\text { CAPRISA } 004 \text { Tenofovir gel } \\
\text { Trial }^{10,22}\end{array}$ & Yes & Yes $^{\mathrm{j}}$ & 0 & 16 & & 82 & 29 & 2 & Monthly & Monthly & Yes & Yes & $\begin{array}{l}\text { OCPs, injectables, IUD, } \\
\text { tubal ligation }^{\mathrm{h}}\end{array}$ & 5 \\
\hline MTN 003 VOICE Trial $^{4}$ & Yes & Yes $^{\mathrm{j}}$ & Ongoing & Ongoing & & Ongoing & Ongoing & Ongoing & Monthly & Monthly & Yes & Yes & Contraception Services ${ }^{\mathrm{k}}$ & Ongoing \\
\hline FACTS 001 Trial $^{5}$ & Yes & Yes $^{\mathrm{j}}$ & Ongoing & Ongoing & & Ongoing & Ongoing & Ongoing & Monthly & Quarterly & Yes & Yes & $\begin{array}{l}\text { OCPs, injectables, IUD, }{ }^{\mathrm{h}} \\
\text { sterilisation, }{ }^{\mathrm{h}} \text { implants }^{\mathrm{h}}\end{array}$ & Ongoing \\
\hline
\end{tabular}

CAPRISA, Centre for the AIDS Programme of Research in South Africa; CONRAD, Contraceptive Research and Development; FACTS, Follow-on African Consortium for Tenfovir Studies; FHI, Family Health International; HPTN, HIV

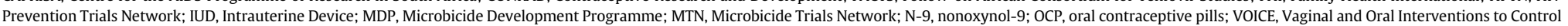
the Epidemic.

Dash: Data not available.

a Percentages were calculated using the primary-analysis population.

b $5 \%$ was reported for 'hormonal' contraception, which included OCPs and injectables.

c Family planning counselling was provided with referral to services if requested.

d Data were supplemented with information from Halpern et al. (2011). ${ }^{31}$

e Trials began with contraception not always provided on site and then changed to on-site management.

${ }^{f}$ Data were supplemented with information from Friedland (2009). ${ }^{36,39}$

g $56 \%$ of the population was considered to have 'effective contraception', which included sterilisation, IUD, or use of injected, implanted or oral contraception.

$\mathrm{h}$ Referred to family planning clinics.

i Data were supplemented with information from Abdool Karim (2007). ${ }^{37}$

${ }^{j}$ Effective contraception for enrollment includes non-barrier methods such as hormonal (oral, injectable), IUD, and sterilisation.

${ }^{k}$ Study staff will provide contraceptive counselling to enrolled participants as needed throughout participation and will facilitate access to contraceptive services through direct service delivery. 
mandating a certain contraceptive method among women who are interested in participating in a trial but who would prefer to use a non-eligible method. To date, no consensus on this has been achieved. Unless there is evidence to the contrary, this strategy is recommended for implementation in clinical trials, as it ensures enrolment of women less likely to default taking contraceptive methods.

\section{On-site provision of free contraceptives}

Accessibility and availability of contraceptive facilities and methods are not always optimal in countries in which these trials are conducted. It might be problematic to therefore prescribe contraceptive practices within a study when the pre-specified methods are neither accessible nor available, or they are not provided as per the local national contraceptive programmes. It is therefore in the best interest of the trial sites to provide eligible methods as well as ongoing care and counselling that are necessary with such a service. Providing family planning services within clinical trials, however, poses extra burdens on the trial resources and infrastructure. This is a specialised service necessitating staff training to provide and switch methods when indicated, manage complications, and to maintain a constant supply. Implementation of this service has proven to be a necessary and rewarding trade-off, as direct temporal effects have been seen in lowering pregnancy rates after implementation of on-site contraceptive provision.

Studies or sites within studies that have introduced on-site provision of contraceptives from the beginning ${ }^{10}$ or sometime during the study ${ }^{24-26}$ have achieved either the lowest or drastic declines in their pregnancy rates after implementation of this strategy. The latter was seen with some sites of the Population Council's Carraguard, HPTN 035 and MDP 301 trials. $^{24-26}$ The Population Council's South Africa sites observed declines in pregnancy rates after revising their contraceptive strategy to include on-site provision after high-incident pregnancies between 2004 and 2005.

At the Medical University of Southern Africa, the incidence decreased from 60 in 2005 to 23 per 100 person years in 2006. At the Medical Research council and University of Cape Town, a decrease in rates from 51 and 43 in 2005 to 32 and 14 per 100 person years in 2006, respectively, were clearly evident. ${ }^{27}$ Similarly, the pregnancy rates in the Microbicide Development Programme 301's Zambia site decreased stepwise from $23 \%$ to $18,6 \%$ to $12,9 \%$ after implementation of contraceptive provision, family planning checklists and training of staff on counselling. ${ }^{28}$ All these studies, however, emphasised one thing in common; the implementation of free on-site provision combined with training of staff and ongoing counselling of participants were together effective in increasing contraceptive uptake and reducing pregnancy rates.

Ongoing counselling by trained staff within clinical trials

Counselling by trained clinical trial staff is an important part of offering contraceptive services, as it affords an opportunity to assess compliance, manage complications and adverse events, and guide method switching. This is important, as it has previously been reported that ineffective contraceptive use, rather than non-use, contributes to unintended pregnancy. ${ }^{29}$ In high-income countries, it has been reported that most women undergo legal termination of pregnancy as a result of contraceptive failure, whereas only a small proportion are caused by non-use of contraception. In Eastern European and South Asian countries, as many as two-thirds of abortions are due to contraceptive failure, and onethird are due to unmet needs for contraception. ${ }^{30}$

In CAPRISA 004, ${ }^{10}$ method switching and the oral contraceptive pill use were significantly associated with high pregnancy incidence. ${ }^{22}$ Because of ongoing monitoring of contraceptive usage at monthly counselling sessions, the need for additional counselling to participants on oral contraceptives owing to the high number of pregnancies that resulted because of inconsistent use was identified. Once implemented, these measures improved adherence to contraception as uptake remained high, and kept pregnancy rates reasonably low, with only $5 \%$ of the women not on a documented contraceptive method at study exit (Table 2). In the Population Council's Carraguard trial, ${ }^{25,27}$ only $20 \%$ were not on a contraceptive method after modification of the contraceptive guidelines to provide support to 
women. In the MDP Zambia site, pregnancy rates dropped from 23 to $12.9 \%$ within 16 months after implementing counselling coupled with on-site provision. ${ }^{26,28}$ This indicates that developing a contraceptive curriculum that is tailor made to suit the needs of the participants is effective in keeping contraceptive uptake and use high in a clinical trial.

Investigators from CAPRISA 004, ${ }^{10}$ Microbicide Development Programme $301,{ }^{26}$ HIV Prevention Trials Network 035, ${ }^{24}$ and Population Council ${ }^{25}$ concluded that the targeted contraceptive curriculum significantly enhanced contraceptive uptake and use, and recommended therefore that future microbicide trials should factor the implementation of these comprehensive curriculums in their protocol development and budgets.

\section{Pregnancy management}

\section{Need for pregnancy management}

Incidental pregnancies during microbicide trials pose numerous challenges, including the possibility of compromising maternal and fetal safety and statistical integrity. In most microbicide trials, pregnancy is an indication to either terminate further study participation or stop the study product, and resume it once the pregnancy chemical tests on urine, blood, or both, revert to being negative. Delayed pregnancy diagnosis may result in inadvertent teratogenecity and adverse pregnancy outcomes. Deferred product resumption after cessation for a pregnancy state may result in unnecessary increases of time off product, whereas pre-clinical pregnancy losses may delay product resumption, with pregnancy rates therefore needing to be kept at a minimum. Some of these challenges are inherent from the demographic characteristics of the population studied, whereas others are inherent from the design of the clinical trial and the route of administration of the study drug. Paradoxically, other challenges result from strategies used to address or minimise the above issues.

The participants in microbicide trials are usually young, sexually active women, who are at high risk of HIV infection as they reside in regions where unprotected heterosexual intercourse is the driver of the epidemic. They are, therefore, concurrently at high risk of falling pregnant as they are in their biologically fertile years. Furthermore, in late-phase effectiveness clinical trials, women are followed up over a minimum period of 12 months, and the use of effective contraceptive methods is essential to avoid pregnancy during this entire time period.

Microbicide drugs in development are administered intravaginally with direct local effects, and may hence alter lower genital tract defences and potentially compromise pregnancy (both maternal and fetal) outcomes. Measures, therefore, need to be taken to minimise incident pregnancies as discussed above, to enhance safety in the advent of a breakthrough pregnancy, or both.

\section{Eligibility criteria}

In order to minimise pregnancy rates and reduce the probability of investigational product exposure to the unborn baby, various strategies from screening and baseline through to follow up and exit visits have been used by different microbicide trials. To date, these strategies included prespecifying pregnancy-related eligibility criteria. Women who were either pregnant at screening or those who intended falling pregnant at any time during the trial were excluded. It has been argued, however, that screening out women based on self-reported pregnancy intentions alone might not be an adequate strategy, as trials that recruited women with no pregnancy intentions over the trial duration still had high pregnancy rates. All trials, with the exception of the MDP 301 trial, ${ }^{26}$ including the Savvy/Ghana trial, ${ }^{9}$ which had the highest pregnancy rates, screened out women on the basis of this criterion.

On the basis of the limited success with this particular criterion, it has been suggested that identifying other pregnancy predictors for inclusion in the screening criteria might improve pregnancy prediction in microbicide trials. Halpern et al., ${ }^{31}$ in an analysis of 6748 women participating in four latephase microbicide trials, found multiparity, living with a man, and frequent unprotected sexual acts 
a week before enrolment to be associated with higher hazards of falling pregnant during the trial. ${ }^{31}$ The risk of pregnancy was lower in older women, in those with a higher education and more sexual partners, and when long-acting contraceptive methods and condoms were used. Blanchard et al. ${ }^{32}$ found an overlap of a significantly higher risk of pregnancy with young age and living with partner, whereas Sibeko et al. ${ }^{22}$ found an overlap with the use of oral contraceptives and condom use. From these three analyses, it might be appropriate to, therefore, recommend the baseline use of long-acting contraceptive methods, young age and living with partner as pregnancy predictors in future microbicide trials.

\section{Safety and statistical integrity during trial conduct}

Because of the unknown and often unquantifiable risk of harm to the unborn baby (teratogenicity) should the mother fall pregnant while exposed to the investigational drug, strategies need to be implemented to, as primary prevention, enhance contraceptive use and prevent unintended pregnancies in microbicide trials. ${ }^{6}$ Should a woman have a breakthrough pregnancy, however, a secondary prevention measure is to minimise exposure to the study drug, particularly before embryogenesis occurs, in order to protect the unborn baby. Minimising drug exposure would entail stopping product use early in pregnancy, before embryogenesis. To achieve this, frequent pregnancy testing and product withdrawal at the first pregnancy test have been used by some trials. Two problems arise with pregnancy detection in the first trimester, namely: false positivity rates with chemical testing are high, and fetal wastage during the first trimester of pregnancy is also high. ${ }^{33}$ Optimising precision of pregnancy detection tests and streamlined testing algorithms to minimise false positivity and offproduct time is critical for efficient trial conduct.

One strategy has been to test enrolled participants on a monthly basis during their scheduled study visits using a highly sensitive beta human chorionic gonadotropin urine test, and placing the participant on immediate product hold should the pregnancy test prove positive. Use of highly sensitive tests and frequent testing for timeous pregnancy diagnosis, however, may increase detection of preclinical pregnancies (chemical pregnancies). Subsequent study product withdrawal for pregnancies that would otherwise have been miscarried spontaneously thereby leads to falsely high pregnancy rates and unnecessary time off product. ${ }^{33}$ These combined strategies have been thought to be a significant contributor to elevated pregnancy rates and statistical sequelae, particularly where a single positive pregnancy test is diagnostic of a pregnancy within a trial setting (Table 3). ${ }^{31}$ Additionally, occurrence of false-positive and chemical pregnancies may raise two ethical concerns: for some women, pregnancy diagnosis alone may result in stress and for others this may be worsened by a sequential pregnancy loss. Chemical and false pregnancies may therefore be of extreme duress to a woman who may have already been informed of a pregnancy diagnosis.

In order to offset falsely elevated pregnancy rates, the Population Council's Carraguard trial ${ }^{25}$ investigators conducted pregnancy testing on a quarterly basis, with the resultant pregnancy rate of $8,4 \%$ at the end of the study. ${ }^{25}$ Alternatively, implementation of two or more successive pregnancy confirmation tests after the first positive test adopted by CAPRISA $004^{10}$ was effective in detecting early pregnancy losses, expediting product re-institution, and thereby reducing time off study product. This strategy only had four out of 54 probable chemical and false pregnancy tests, ${ }^{22}$ a statistic that was much lower than the estimated $25 \%$ chemical pregnancy rates in a population. ${ }^{33}$ Schreiber et al. $^{33}$ recommend carrying out a pregnancy test only after a missed period, which would be similar to a normal clinical setting. This approach may only minimally increase product exposure duration, as they showed that this method would add 12 days or less of in-utero product exposure. Effectiveness of the latter strategy is in reducing false high pregnancy rates is yet to be observed.

Lastly, the following have been effective in minimising time off product: (1) continued pregnancy testing for the first 3 months of pregnancy after the first positive test to exclude unrecognised early preclinical pregnancy loss; (2) the former, combined with continued regular study visits by pregnant participants for early detection of delivery and pregnancy termination; (3) and immediate product re-institution at the occurrence of a negative test. Carrying out blood beta 
Table 3

Pregnancy management and outcomes in microbicide trials to date.

\begin{tabular}{|c|c|c|c|c|c|c|c|c|c|c|c|c|c|}
\hline \multirow{2}{*}{$\begin{array}{l}\text { Microbicide } \\
\text { trials }\end{array}$} & \multicolumn{2}{|l|}{ Screening } & \multicolumn{11}{|l|}{ Follow up } \\
\hline & $\begin{array}{l}\text { Exclusion } \\
\text { for } \\
\text { pregnancy }\end{array}$ & $\begin{array}{l}\text { Exclusion } \\
\text { for } \\
\text { wanting } \\
\text { Pregnancy }\end{array}$ & $\begin{array}{l}\text { Frequency } \\
\text { of } \\
\text { pregnancy } \\
\text { tests }\end{array}$ & $\begin{array}{l}\text { Censored at } \\
\text { pregnancy } \\
\text { diagnosis }\end{array}$ & $\begin{array}{l}\text { Timing of } \\
\text { product } \\
\text { hold }\end{array}$ & $\begin{array}{l}\text { Timing of } \\
\text { product re- } \\
\text { institution }\end{array}$ & $\begin{array}{l}\text { Chemical } \\
\text { Pregnancies } \\
\text { (N) }\end{array}$ & $\begin{array}{l}\text { Fetal } \\
\text { outcomes }\end{array}$ & $\begin{array}{l}\text { Maternal } \\
\text { outcomes }\end{array}$ & $\begin{array}{l}\text { Pregnancies } \\
\text { (N) }\end{array}$ & $\begin{array}{l}\text { Person- } \\
\text { years }\end{array}$ & $\begin{array}{l}\text { Person years } \\
\text { off product } \\
\text { owing to } \\
\text { pregnancy } \\
\text { (of total } \\
\text { person years) }\end{array}$ & $\begin{array}{l}\text { Pregnancy } \\
\text { Rate per } \\
100 \text { person } \\
\text { years (95\% } \\
\text { confidence } \\
\text { interval) }\end{array}$ \\
\hline \multicolumn{14}{|l|}{ Surfactants } \\
\hline $\begin{array}{l}\text { Kenya N-9 } \\
\text { Sponge } \\
\text { Trial }^{13}\end{array}$ & - & - & - & - & - & - & - & - & - & - & - & - & - \\
\hline $\begin{array}{l}\text { FHI N-9 Film } \\
\text { Trial }^{14}\end{array}$ & Yes & Yes & - & - & $\begin{array}{l}\text { Withdrawal } \\
\text { for pregnancy }\end{array}$ & - & - & - & - & 5 & - & - & - \\
\hline $\begin{array}{l}\text { Low-dose N-9 } \\
\text { gel Trial }^{15}\end{array}$ & Yes & - & - & - & - & - & - & - & - & - & - & - & - \\
\hline $\begin{array}{l}\text { UNAIDS COL- } \\
1492 \text { Trial } \\
(\mathrm{N}-9)^{16}\end{array}$ & Yes & Yes & - & - & $\begin{array}{l}\text { Withdrawal } \\
\text { for pregnancy }\end{array}$ & - & - & - & - & 10 & - & - & - \\
\hline $\begin{array}{l}\text { FHI Savvy } \\
\text { Trial/ } \\
\text { Ghana }\end{array}$ & Yes & Yes & Monthly & Per-protocol & $\begin{array}{l}\text { Positive } \\
\text { pregnancy test }\end{array}$ & $\begin{array}{l}\text { Negative } \\
\text { pregnancy test }\end{array}$ & - & $\begin{array}{l}13(2.14 \%) \\
\text { spontaneous } \\
\text { abortions } 40 \text { live } \\
\text { births }\end{array}$ & $\begin{array}{l}\text { Seven (intervention), } \\
13 \text { (placebo) adverse } \\
\text { events related to } \\
\text { pregnancy, } \\
\text { puerperium and } \\
\text { perinatal conditions }\end{array}$ & 769 & 1203 & $150.9(10 \%)$ & $\begin{array}{l}63.9 \% \\
(59.5-68.6)\end{array}$ \\
\hline $\begin{array}{l}\text { FHI Savvy } \\
\text { Trial/ } \\
\text { Nigeriaa }^{20, a}\end{array}$ & Yes & Yes & Monthly & Per-protocol & $\begin{array}{l}\text { Positive } \\
\text { pregnancy test }\end{array}$ & $\begin{array}{l}\text { Negative } \\
\text { pregnancy test }\end{array}$ & - & - & $\begin{array}{l}0 \text { (intervention), } \\
\text { three (placebo) } \\
\text { adverse events } \\
\text { related to pregnancy, } \\
\text { puerperium and } \\
\text { perinatal conditions }\end{array}$ & 552 & 1496 & $88.1(5 \%)$ & $\begin{array}{l}36.9 \% \\
(33.9-40.1)\end{array}$ \\
\hline \multicolumn{14}{|c|}{ Buffers and blockers } \\
\hline $\begin{array}{l}\text { CONRAD } \\
\text { Cellulose } \\
\text { Sulfate } \\
\text { Trial }^{17, a}\end{array}$ & Yes & Yes & Monthly & Per-protocol & $\begin{array}{l}\text { Positive } \\
\text { pregnancy test }\end{array}$ & $\begin{array}{l}\text { Negative } \\
\text { pregnancy test }\end{array}$ & & $\begin{array}{l}110(56 \%) \\
\text { spontaneous or } \\
\text { induced abortions } \\
85(43 \%) \text { live births }\end{array}$ & $\begin{array}{l}15 \text { abortion or } \\
\text { abortion-related } \\
\text { events } s^{\mathrm{b}}\end{array}$ & 197 & 755 & $56.4(7 \%)$ & $\begin{array}{l}26.1 \% \\
(22.6-30.1)\end{array}$ \\
\hline FHI CS Trial ${ }^{18, a}$ & Yes & Yes & Monthly & Per-protocol & $\begin{array}{l}\text { Positive } \\
\text { pregnancy test }\end{array}$ & $\begin{array}{l}\text { Negative } \\
\text { pregnancy test }\end{array}$ & - & $\begin{array}{l}265(86 \%) \\
\text { spontaneous or } \\
\text { induced abortions } \\
40(13 \%) \text { live births }\end{array}$ & - & 308 & 1073 & $60.4(5 \%)$ & $\begin{array}{l}28.7 \% \\
(25.6-32.1)\end{array}$ \\
\hline $\begin{array}{l}\text { Population } \\
\text { Council } \\
\text { Carraguard } \\
\text { Trial }^{25, d}\end{array}$ & Yes & Yes & Quarterly & Per-protocol & $\begin{array}{l}\text { Withdrawal for } \\
\text { pregnancy }\end{array}$ & - & - & $\begin{array}{l}146(21 \%) \\
\text { terminations } \\
364(53 \%) \text { live } \\
\text { births }\end{array}$ & - & 682 & 8119 & - & $\begin{array}{l}8.4 \% \\
(7.8-9.1)\end{array}$ \\
\hline
\end{tabular}




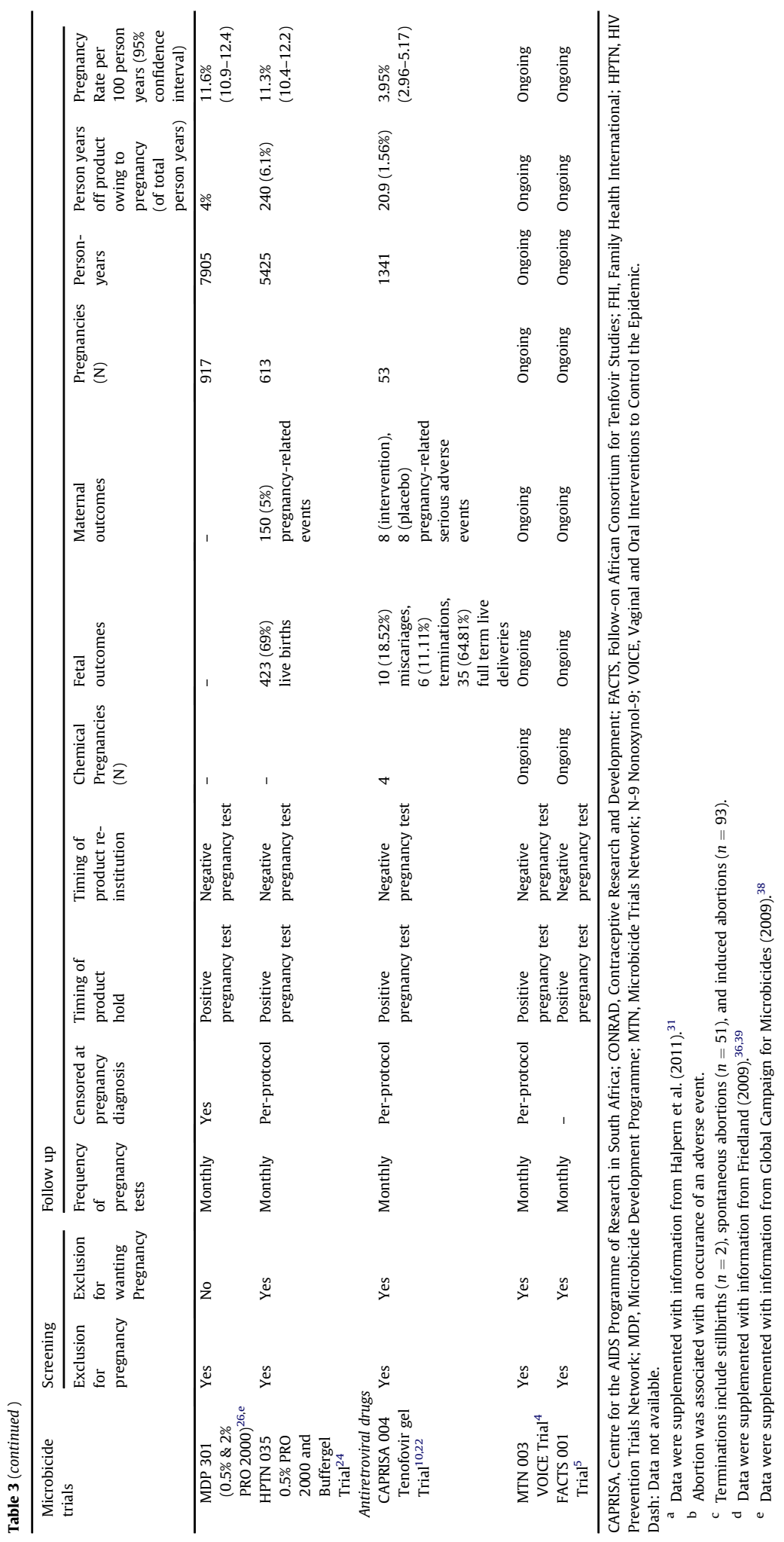


human chorionic gonadotropin quantitation in the advent of ambiguous urine results has also been recommended.

\section{Sexual and reproductive health outcomes}

Incident pregnancies are avoided in microbicide studies for safety of the women who fall pregnant and their babies, but also for protection of a range of sexual and reproductive health functions. As microbicides are currently in development with limited understanding of drug effects after intravaginal administration and before sexual exposure, the full spectrum of potential toxicities to sexual and reproductive abilities is not fully understood. It is important, therefore, that ongoing studies systemically collect data in this regard.

Fertility may be compromised when sperm, exposed to study product during intercourse, is compromised and thereby reduces its ability to fertilise an egg. After conception, because of direct passage of the study product up through the cervical canal into the uterus, the drug may potentially lead to pregnancy losses and preterm labour with continued drug use late into pregnancy. Embryos that are conceived while the mother is using the study product may be harmed and the babies born with anomalies.

The discovery that a microbicide induces miscarriages, reduces fertility, causes birth defects, and compromises maternal health would likely doom its development. Important safeguards, therefore, need to be implemented to minimise such incidents, and active monitoring during the trial to detect any of these adverse events should be standard practice. Additionally, the pregnant state may affect behaviour around study product use or efficacy and the virulence of HIV, which in turn may increase incident HIV infections and complicate trial outcomes. ${ }^{34}$ Lastly, women may electively terminate pregnancies out of concerns for teratogenicity or for fear of trial participation termination.

Data are usually collected on pregnancy outcomes within microbicide trials, and include miscarriages, terminated pregnancies, preterm labour and full-term births, with and without a live birth. These are then compared, for that particular community, with background rates to indirectly assess the effect of the study drug on each of the outcomes, the results of which are discussed at the protocol safety and monitoring team meetings and data and safety monitoring board meetings. With most of the 1.74 billion reproductive-age females being sexually active, and a probability of conception during unprotected coitus of three in $100,{ }^{35}$ as many as 720 million conceptions may occur each year.

Tsui et al. ${ }^{29}$ reported that, on the basis of population studies, most conceptions (60-70\%) will be spontaneously miscarried, leaving about 239 million identified pregnancies, of which 136.2 million will progress to live births, 33 million being unwanted. ${ }^{29}$ An additional 46 million pregnancies will be electively terminated. Anything in excess of the documented reproductive health outcomes for any particular community needs to be investigated closely.

Not all clinical trials have systematically documented and reported data in this regard in the previous trials (Table 3 ) $^{31}$; however, for the trials that did, there have not been any concerning safety effects on sexual and reproductive health outcomes. Of note, however, is that studies that systematically collected these data, such as CAPRISA $004,{ }^{10}$ assessed babies once off in the immediate postpartum period. It is recommended that trials yet to be implemented follow babies longitudinally for prolonged periods of time.

\section{Conclusion}

Microbicide trials that recruit sexually active women in their reproductive age are fraught with reproductive health issues. If these are inadequately addressed, they may compromise the conduct of the trial and the integrity of the results. From this review, it is evident that, where a structured programme is used to address contraception and pregnancy issues, pregnancy rates are significantly lowered, the probability of harm to the unborn baby reduced, and time off product minimised. 
Where contraception is used to prevent pregnancy, uptake and use of contraceptive methods is enhanced by ensuring that all methods are provided free on-site by trained study staff during intensive and supportive counselling sessions at every study visit. Enrolment criteria require careful screening to avoid, including women who are likely to become pregnant while on study; however, this might be viewed as coercive by some if not implemented properly. Frequent testing for pregnancy at each visit using sensitive tests, coupled with successive repeated testing after a single positive test, is effective in early pregnancy detection while ensuring low false positive tests and continued pregnancy states. Immediate product withdrawal at pregnancy diagnosis reduces the period of exposure to the drug by the unborn baby, whereas immediate resumption in the postpartum period is effective in minimising time lost off product.

Continued follow up throughout the pregnancy allows immediate detection of parturition and assessment of pregnancy outcomes. The research gaps identified were numerous; however, one of the greatest seems to be use of microbicides throughout pregnancy in order to ascertain safety of use in the population who are also at risk of HIV acquisition.

Finally, although specific steps have been initiated to provide safety data on microbicides for pregnant women and their babies, much more research needs to be carried out at the various stages of pregnancy. Subsequent studies should follow up infants born after exposure to microbicides for prolonged periods after birth.

\section{Practice points}

- Intravaginally applied microbicides, as a female-initiated strategy, aim to empower women to protect themselves against HIV. Because microbicide trials enrol women in reproductive age groups, these trials are fraught with reproductive challenges, which affect trial conduct and integrity of results.

- Microbicide trials need to have intensive contraceptive and pregnancy management programmes to address challenges efficiently and adequately posed by incident pregnancies during the trial.

- For contraceptive-related recommendations, trials need to aim for $100 \%$ contraceptive uptake and use of highly effective contraceptive methods throughout the trial by:

specifying eligibility criteria, including use of contraceptive methods;

separating contraceptive curriculum, which includes intensive counselling;

providing contraceptive counselling at each visit by trained family planning staff;

respecting women's choice of method;

providing a wide range of contraceptives on-site;

adequately and continuously documenting choice of method; and

diligently and regularly monitoring, reviewing and supporting contraceptive use of each participant at each visit.

- Pregnancy-related recommendations: these trials need to aim for low pregnancy rates and increased surveillance in order to diagnose pregnancies reliably and sufficiently early, reduce time to pregnancy detection, detect subclinical pregnancies, and re-institute product by:

specifying eligibility criteria, including pregnancy intentions;

testing for pregnancy at every visit;

using highly sensitive and specific pregnancy tests;

repeating tests successively in order to detect subclinical pregnancy losses;

continuously following up pregnant women until pregnancy outcome has been established; and

providing clear guidelines on product withdrawal and re-institution. 


\section{Research agenda}

- From the completed microbicide trials to date, increased pregnancy-related adverse outcomes have not been reported. None of the trials implemented continued product use in pregnancy. Consequently, the effects of using microbicides throughout pregnancy on the mother and fetus is minimally understood. This is because, in clinical trials to date, the product has been withdrawn immediately once pregnancy is diagnosed.

- Pregnant women continue to be sexually active in pregnancy, and incident infections have been reported in late trimesters of pregnancy. We, therefore, need to design and conduct research that addresses the following issues:

application of the microbicide intravaginally may alter the microbial vaginal milieu and hence affect the local immune system. We need to understand the effect of microbicides on fertility;

currently some microbicides are used pericoitally; the effect of microbicide use on the woman's ability to conceive needs to be understood;

does microbicide use around the time of conception increase the risk of miscarriage?

- The pharmacokinetics and pharmacodynamics of microbicides are not completely understood; yet, these influence the effect of microbicides on pregnancy outcomes. Does microbicide use in the first trimester increase the risk of fetal anomalies? Or after the first trimester increase the risk of preterm labor? Or in pregnancy increase adverse maternal outcomes such as haemorrhage?

- Antiretroviral-based microbicides may be absorbed systemically: is the microbicide application adequate to use for prevention of mother-to-child transmission? What is the effect of microbicide use on development of resistance?

- For serodicordant couples planning a pregnancy, can targeted periconceptual use of microbicides be adequate to prevent both sexual and mother-to-child transmission?

\section{Acknowledgement}

Gabriel M Cohen was supported by the National Institutes of Health Office of the Director, Fogarty International Center, Office of AIDS Research, National Cancer Center, National Eye Institute, National Heart, Blood, and Lung Institute, National Institute of Dental and Craniofacial Research, National Institute On Drug Abuse, National Institute of Mental Health, National Institute of Allergy and Infectious Diseases, and National Institutes of Health Office of Women's Health and Research through the Fogarty International Clinical Research Scholars and Fellows Program at Vanderbilt University (R24 TW007988) and the American Relief and Recovery Act. The Columbia University-Southern African Fogarty AIDS International Training and Research Programme (AITRP), funded by the Fogarty International Center, National Institutes of Health (grant D43TW00231), supported the training of Sengeziwe Sibeko.

\section{References}

1. UNAIDS. Report on the global AIDS epidemic update. Geneva, Switzerland: Joint United Nations Programme on HIV/AIDS, 2008.

*2. Stein ZA. HIV prevention: the need for methods women can use. Am J Public Health 1990; 80: 460.

*3. Padian N, McCoy SI, Balkus JE et al. Weighing the gold in the gold standard: challenges in HIV prevention research. AIDS 2010; 24: 621.

4. Chirenje ZM, Marrazzo J. MTN-003 Protocol 2.0; 2010; http://www.mtnstopshiv.org/sites/default/files/attachments/MTN003_FINAL_Version_2.0_31DEC2010.pdf (last accessed 22 January 2012).

5. Facts Consortium: Working Together to Prevent HIV - facts 001 study [Internet]. [cited 2012 Feb 3]; Available from: http:// www.facts-consortium.co.za/?page_id=83.

*6. Raymond EG, Taylor D, Cates Jr. W et al. Pregnancy in effectiveness trials of HIV prevention agents. Sex Transm Dis 2007; 34: 1035-1039. 
*7. Lagakos SW \& Gable AR. Methodological challenges in biomedical HIV prevention trials. Washington, District of Columbia: National Academy of Sciences, 2008.

*8. Smart T. High rates of pregnancy pose challenges for microbicide trials 2006, http://www.aidsmap.com/Microbicides-2006High-rates-of-pregnancy-pose-challenges-for-microbicide-trials/page/1423789/ (last accessed 22 January 2012).

9. Peterson L, Nanda K, Opoku BK et al. SAVVY (C31G) gel for prevention of HIV infection in women: a Phase 3, double-blind, randomized, placebo-controlled trial in Ghana. PloS One 2007; 2: e1312.

10. Abdool Karim Q Abdool Karim SS, Frohlich JA et al. Effectiveness and safety of tenofovir gel, an antiretroviral microbicide, for the prevention of HIV infection in women. Science 2010; 329: 1168-1174.

11. Singh S, Sedgh G \& Hussain R. Unintended pregnancy: worldwide levels, trends, and outcomes. Stud Fam Plann 2010; 41: 241-250.

12. Singh S, Darroch J \& Ashford L. Meeting the need for modern family planning services. In: Adding it up: the costs and benefits of investing in family planning and maternal and newborn health. New York, NY: Guttmacher Institute and United Nations Population Fund, 2009, pp. 16-20.

13. Kreiss JK, Ngugi E, Holmes K et al. Efficacy of nonoxynol 9 contraceptive sponge use in preventing heterosexual acquisition of HIV in Nairobi prostitutes. JAMA 1992; 268: 477-482.

14. Roddy R, Zekeng L, Ryan KA et al. A controlled trial of nonoxynol 9 film to reduce male-to-female transmission of sexually transmitted diseases. N Engl J Med 1998; 339: 504-510.

15. Richardson BA, Lavreys L, Martin HL et al. Evaluation of a low-dose nonoxynol-9 gel for the prevention of sexually transmitted diseases: a randomized clinical trial. Sex Transm Dis 2001; 28: 394-400.

16. Van Damme L, Ramjee G, Alary M et al. Effectiveness of COL-1492, a nonoxynol-9 vaginal gel, on HIV-1 transmission in female sex workers: a randomised controlled trial. Lancet 2002; 360: 971-977.

17. Van Damme L, Govinden R, Mirembe FM et al. Lack of effectiveness of cellulose sulfate gel for the prevention of vaginal HIV transmission. N Engl J Med 2008; 359: 463-472.

18. Halpern V, Ogunsola F, Obunge $\mathrm{O}$ et al. Effectiveness of cellulose sulfate vaginal gel for the prevention of HIV infection: results of a Phase III trial in Nigeria. PloS One 2008; 3: e3784.

*19. Mauck CK, Freziers RG, Walsh TL et al. Noncomparative contraceptive efficacy of cellulose sulfate gel. Obstet Gynecol 2008; 111: 739.

20. Feldblum PJ, Adeiga A, Bakare R et al. SAVVY vaginal gel (C31G) for prevention of HIV infection: a randomized controlled trial in Nigeria. PloS One 2008; 3: e1474.

*21. National Institutes of Health (NIH). Pregnancy and Contraception in Microbicide Development Meeting. March 2009; http://www.nichd.nih.gov/about/meetings/2009/031009.cfm. (last accessed 22 January 2012)

22. Sibeko S, Baxter C, Yende $\mathrm{N}$ et al. Contraceptive choices, pregnancy rates, and outcomes in a microbicide trial. Obstet Gynecol 2011; 118: 895-904.

*23. Trussell J. Contraceptive failure in the United States. Contraception 2004; 70: 89-96.

24. Abdool Karim SS, Richardson BA, Ramjee G et al. Safety and effectiveness of BufferGel and 0.5\% PRO2000 gel for the prevention of HIV infection in women. AIDS 2011; 25: 957-966.

25. Skoler-Karpoff S, Ramjee G, Ahmed K et al. Efficacy of Carraguard for prevention of HIV infection in women in South Africa: a randomised, double-blind, placebo-controlled trial. Lancet 2008; 372: 1977-1987.

26. McCormack S, Ramjee G, Kamali A et al. PRO2000 vaginal gel for prevention of HIV-1 infection (Microbicides Development Programme 301): a phase 3, randomised, double-blind, parallel-group trial. Lancet 2010; 376: 1329-1337.

27. Cele N, Palanee T, Myeni N et al. Impact of provision of hormonal contraception on pregnancy incidence in women enrolled in the phase 3 Carraguard clinical trial at three sites in South Africa 2008, http://www.popcouncil.org/pdfs/Microbicides2008/ Cele_Poster.pdf (last accessed 22 January 2012).

28. Chisembele M. Pregnancy and contraception in microbicide development - Zambia MDP. In: Pregnancy and Contraception in Microbicide Development. Washington, DC: NIH, 2009.

29. Tsui AO, McDonald-Mosley R \& Burke AE. Family planning and the burden of unintended pregnancies. Epidemiol Rev 2010; 32: $152-174$.

30. Westoff CF. DHS Analytical Studies No. 8: recent trends in abortion and contraception in 12 Countries. Calverton, Maryland: ORC Macro, 2005.

*31. Halpern V, Lie C-C, Feldblum PJ et al. Predictors of pregnancy in microbicide trials. Contraception 2011; 83: 436-440.

32. Blanchard K, Bostrom A, Montgomery E et al. Contraception use and effectiveness among women in a trial of the diaphragm for HIV prevention. Contraception 2011; 83: 556-563.

*33. Schreiber CA, Sammel M, Hillier SL et al. A little bit pregnant: modeling how the accurate detection of pregnancy can improve HIV prevention trials. Am J Epidemiol 2009; 169: 515.

34. Gray RH, Li X, Kigozi G et al. Increased risk of incident HIV during pregnancy in Rakai, Uganda: a prospective study. Lancet 2005; 366: 1182-1188.

35. Wilcox AJ, Dunson DB, Weinberg CR et al. Likelihood of conception with a single act of intercourse: providing benchmark rates for assessment of post-coital contraceptives. Contraception 2001; 63: 211-215.

36. Friedland B. Pregnancy/Contraception in Carraguard Phase 3 Trial. In: Pregnancy and Contraception in Microbicide Development. Washington, DC: NIH, 2009.

37. Abdool Karim SS. HPTN 035 Protocol 3.0 2007, http://www.mtnstopshiv.org/sites/default/files/attachments/HPTN035v3.pdf (last accessed 22 January 2012).

38. Global Campaign for Microbicides (GCM). GCM Advocates Call on HPTN 035 Results Wednesday 11th February at 9AM EST, 2009; http://www.global-campaign.org/clientfiles/HPTN 035 Results Release Advocates Call Notes.pdf (last accessed 22 January 2012).

39. Morrison CS, Skoler-Karpoff S, Kwok C et al. Hormonal Contraception and the Risk of HIV Acquisition among Women in South Africa. AIDS 2012; 25: 1-8. 